\title{
EL ESTUDIO DEL PROFESORADO UNIVERSITARIO EN LA HISTORIA CONTEMPORÁNEA
}

\author{
The study of university teachers in contemporary history
}

\section{Jean-Louis Guereña*}

Fecha de recepción: 23/09/2014 • Fecha de aceptación: 04/11/2014

Resumen. Hoy en día, se puede afirmar que se halla plenamente consolidado como objeto historiográfico el mundo de la universidad española en los siglos XIX y XX y en particular el profesorado universitario. En particular, el enfoque prosopográfico ya viene siendo una práctica relativamente habitual entre los investigadores que se acercan con algún detenimiento al estudio de la historia del profesorado universitario. La fecunda y ambiciosa iniciativa de elaborar un Diccionario de catedráticos españoles de Derecho (1847-1943) supone un salto cualitativo importante que merece destacarse en ese ámbito. También queremos recordar a continuación el interés que siguen teniendo los escalafones de antigüedad de catedráticos de universidad para un enfoque sociológico del conjunto del profesorado universitario en la época contemporánea, limitado desde luego al cuerpo de los catedráticos.

En efecto, tanto el Diccionario como los escalafones adolecen de un «defecto» originario y comprensible ya que tan sólo enfocan el cuerpo de catedráticos. Dejan, pues, de lado no sólo a las «mujeres universitarias» (hasta 1953) — salvo el caso aislado y no representativo de Emilia Pardo Bazánque habían logrado ingresar en una universidad como profesoras auxiliares, sino, en general, a todos los profesores no catedráticos. Otra «variable» no contemplada es la de los orígenes sociales del profesorado universitario, a lo que podríamos añadir otros elementos referentes a la «condición universitaria». Desbordamos así la historia universitaria «académica» para ir hacia una historia «social» del profesorado universitario, taller inmenso que sólo puede llevarse a cabo de manera colectiva e interdisciplinar.

Palabras clave: Catedráticos. Historiografía. Profesorado. Universidad. Profesoras universitarias.

* ICD, Université François-Rabelais, Tours. 3, Rue des Tanneurs. 37041 Tours Cedex. Francia. jean-louis.guerena@univ-tours.fr

Cómo citar este artículo: Guereña, Jean-Louis, «El estudio del profesorado universitario en la historia contemporánea», Historia y Memoria de la Educación, 1 (2015): 395-417. 
Abstract. Today we are justified in affirming that the world of the nineteenth and twentieth century Spanish university, and in particular its teachers, has become a fully consolidated subject of historiographic research. In particular, the prosopographical approach has become a comparatively common practice among researchers focusing on the study of the history of university teachers. In this regard, the ambitious, in-depth initiative undertaken in the preparation of the Diccionario de catedráticos españoles de Derecho (1847-1943) (Dictionary of Spanish Law Professors) was a milestone in the field. We will also focus on the continuing interest regarding the levels of hierarchy observed among full professors, and we will approach this issue from a sociological perspective that takes into account the body of professors as a whole.

In truth, both the Dictionary of Spanish Law Professors and the study of hierarchies suffer from a "flaw" dating from their very conception, namely, that they only take into consideration the body of full professors. In doing so they exclude the "university women» (until 1953) as well as anyone who was not a full professor. Another "variable» that was not taken into consideration was the social background of the professors, alongside other aspects that could be considered to pertain to the "university condition». Thus our perspective goes beyond a purely «academic» history of the university, providing instead a «social» history of university professors. An undertaking as hefty as this can only be carried out in a collective, interdisciplinary fashion.

Key Words: Professors. Historiography. University Teachers. Universities. Women university teachers.

A Julio Ruiz, Berrio, in memoriam

Hoy en día, se puede afirmar que se halla plenamente consolidado como objeto historiográfico el mundo de la universidad española en la época contemporánea (o sea los siglos XIX y XX, sobre todo tras las reformas de 1845), en particular en cuanto a sus diferentes espacios y actores. Es notablemente el caso en el campo jurídico, pues en buena parte, como en otros países, ${ }^{1}$ la historia del Derecho resulta ser la historia de su enseñanza universitaria y por lo tanto de las Facultades de Derecho en general, de sus profesores, de sus estudiantes y de sus distintos planes de estudio en su trayectoria evolu-

\footnotetext{
1 Jean-Louis Guereña, «La historia de la enseñanza superior en Francia. Una aproximación historiográfica», en Miscelánea Alfonso IX, 2008, ed. Luis Enrique Rodríguez San Pedro Besares y Juan Luis Polo Rodríguez (Salamanca: Universidad de Salamanca, 2009), 265.
} 
tiva. ${ }^{2}$ Nada extraño, pues, que la historia universitaria haya sido cultivada esencialmente por juristas, con sus métodos y sus objetivos propios que han ido evolucionando en el tiempo.

Acerca de los profesores de universidad en la historia, estamos así ya muy lejos del diagnóstico más que pesimista que podía establecer hace un cuarto de siglo uno de los pioneros de la historia universitaria en España (y también en México), Mariano Peset Reig (nacido en 1934), profesor de Historia del Derecho y de las Instituciones en la Universidad de Valencia, adjunto desde 1967 y catedrático desde $1986 .^{3}$ Según él, a la pregunta «¿quiénes son los universitarios?», contestaba en 1989 que tan solo se les podía considerar entonces «desde una historia institucional» como meras «sombras en el claustro», por lo tanto como perfectos desconocidos o casi, pues «el análisis de los catedráticos no parece haber avanzado demasiado, ni aquí ni en otros países». ${ }^{4}$

Pero el balance historiográfico establecido hace unos pocos años - ya algo desfasado, como más o menos rápidamente ocurre a todos los «estados de la cuestión»- acerca de la historia universitaria en España durante los siglos XIX y XX (y para el periodo 1981-2009) muestra claramente los avances realizados durante aquellos casi treinta años de investigaciones llevadas a cabo en torno a la historia del profesorado universitario y, en general, de los actores de la vida universitaria. ${ }^{5}$ No vamos, pues, a repetir

\footnotetext{
2 Para el caso español, ver Manuel Martínez Neira, «Los orígenes de la historia del derecho en la universidad española», Cuadernos del Instituto Antonio de Nebrija de estudios sobre la Universidad, 3 (2000): 71-164; Alfredo Gallego Anabitarte, Formación y enseñanza del Derecho público en España (1769-2000). Un ensayo crítico (Madrid: Marcial Pons, 2002), 13-31; María Encarnación Gómez Rojo, «La Historia de las Universidades como objeto de la Historia del derecho en su orientación institucional», Revista de estudios histórico-jurídicos, 28 (2006): 577-587.

${ }^{3}$ Ignacio Peiró Martín y Gonzalo Pasamar Alzuria, Diccionario Akal de Historiadores españoles contemporáneos (Madrid: Akal, 2002), 490-491; Enrique González González, Armando Pavón Romero, Yolanda Blasco Gil y Leticia Pérez Puente, «Mariano Peset, historiador de las universidades, historiador de la universidad de México», prólogo a Mariano Peset, Obra dispersa (México: Universidad Nacional Autónoma de México-Instituto de Investigaciones sobre la Universidad y la Educación-Ediciones de Educación y Cultura, 2011), 9-35.

${ }^{4}$ Mariano Peset, «Prólogo», en Claustros y Estudiantes (Valencia: Universidad de Valencia. Facultad de Derecho, 1989), vol. I, XXII-XXIII. Desde luego, Mariano Peset se refería a la época moderna pero sus consideraciones pueden aplicarse también a la época contemporánea.

5 Jean-Louis Guereña, «La universidad: vida universitaria», en Nuevas miradas historiográficas sobre la educación en la España de los siglos XIX y XX, ed. Jean-Louis Guereña, Julio Ruiz Berrio y Alejandro Tiana Ferrer (Madrid: Ministerio de Educación, 2010), 159-181 y «Los actores de la vida universitaria en la España de los siglos XIX y XX. Una revisión historiográfica (1981-2009)», Cahiers de civilisation espagnole contemporaine, 8, (2011), consultado el 1 de setiembre de 2014, doi: 10.4000/ccec.3768. Ver también José María Hernández Díaz, «Universidad: aspectos institucionales», en Nuevas miradas historiográficas sobre la educación en la España de los siglos XIX y XX, 143-158.
} 
lo que ya indicamos entonces, pero recogemos, ampliamos y completamos aquí algunos de los elementos presentados en aquella ocasión.

Cabe señalar en particular que el enfoque prosopográfico, sobre el cual nos detendremos primero, ya viene siendo una práctica relativamente habitual entre los investigadores que se acercan con algún detenimiento al estudio de la historia del profesorado universitario. La fecunda y ambiciosa iniciativa de elaborar un Diccionario de catedráticos españoles de Derecho responde bien evidentemente a esta preocupación y supone un salto cualitativo importante que merece destacarse en ese ámbito. También queremos recordar a continuación el interés que siguen teniendo los escalafones de antigüedad de catedráticos de universidad para un enfoque sociológico del conjunto del profesorado universitario en la época contemporánea, limitado desde luego al cuerpo de los catedráticos.

En efecto, tanto el Diccionario de catedráticos españoles como los escalafones adolecen de un «defecto» originario y comprensible ya que tan sólo enfocan el cuerpo de catedráticos. Dejan, pues, de lado no sólo a las «mujeres universitarias» (para la época considerada y hasta 1953, salvo el caso aislado y no representativo de Emilia Pardo Bazán) que habían logrado ingresar en una universidad como profesoras auxiliares, sino, en general, a todos los profesores no catedráticos que constituyen sin embargo otros actores universitarios que no se pueden dejar de lado. Otra «variable» que no contemplan los escalafones es la de los orígenes sociales del profesorado universitario, a lo que podríamos añadir otros elementos referentes a la «condición universitaria». Desbordamos así la historia universitaria «académica» para ir hacia una historia «social» del profesorado universitario, taller inmenso que sólo puede llevarse a cabo de manera colectiva e interdisciplinar.

\section{EL ENFOQUE PROSOPOGRÁFICO. EL DICCIONARIO DE CATEDRÁTICOS ESPAÑOLES DE DERECHO}

Básicamente, los estudios sobre el profesorado universitario en la época contemporánea se han realizado a partir de 1981 por centros universitarios, por facultades o por periodos, a menudo combinando varios de estos parámetros. ${ }^{6}$ Ya existían anteriormente algunos catálogos de profesores

6 Guereña, «La universidad: vida universitaria», 168-172. 
universitarios con provechosas indicaciones bio-bibliográficas, como los realizados para la Universidad de Granada de 1845 a 1935 y la Facultad de Filosofía y Letras de la universidad de Madrid ${ }^{7}$. Por facultades, cabe resaltar la atención prestada a los juristas, o sea a los profesores de la Facultad de Derecho, como es el caso, por ejemplo, de la monografía de Yolanda Blasco Gil sobre la Facultad de Derecho de la Universidad de Valencia durante la Restauración o del "Índice de los profesores de las Facultades de Derecho de España del siglo XIX relacionados con materias filosófico-jurídicas» elaborado por Ana Llano Torres y Salvador Rus Rufino. ${ }^{8}$

$\mathrm{Y}$, pese a que la historia universitaria, y por lo tanto la del profesorado universitario, se siga moviendo por lo general dentro de un espacio local concreto (referido a tal o cual universidad) y de una lógica disciplinar (por facultad y a veces por cátedra), se ha avanzado ya en el marco de la perspectiva prosopográfica, que no es propia de la historia universitaria y que ha renovado por completo el género de la biografía. ${ }^{9}$ La prosopografía universitaria, o biografía colectiva del profesorado universitario como cuerpo profesional, se ha impuesto en la historia universitaria como método y herramienta de trabajo, recogiendo algunas de las orientaciones de trabajo abiertas en otros países, como en Francia, en particular por Christophe

\footnotetext{
7 Juan A. Ramallo Ortiz, Catálogo de Profesores de la Universidad de Granada (1845-1935) (Granada: Universidad de Granada, 1976); Pilar Parra Garrigues, Historial de la Facultad de Filosofía y Letras de la Universidad de Madrid (Ensayo bio-bibliográfico) (Madrid: Universidad Complutense, 1956). Cabe añadir las biografías de algunos profesores del siglo XIX de la Facultad de Filosofía y Letras de la Universidad de Madrid redactadas por Mario Pedrazuela Fuentes y colgadas en 2013-2014 en la página «Rinconete» del Instituto Cervantes bajo el título de «Vidas filológicas». Por otra parte, en alguna manera, pues no todos los historiadores reseñados son académicos, se puede tener en cuenta el ya mencionado Diccionario Akal de Historiadores españoles contemporáneos de Ignacio Peiró y Gonzalo Pasamar (2002).

8 Yolanda Blasco Gil, La Facultad de Derecho de Valencia durante la Restauración (1875-1900), prólogo de Mariano Peset (Valencia: Universitat de València [Col.lecció Cinc Segles, 7], 2000), 259-322 («El cuerpo profesoral: poder social y prestigio académico»); Ana Llano Torres y Salvador Rus Rufino, Historia del pensamiento filosófico y jurídico. La enseñanza de las disciplinas iusfilosóficas en la Universidad española del siglo XIX y sus protagonistas (León: Universidad de León, 1997), 27-120.

9 Lawrence Stone, «Prosopografía», en El pasado y el presente (México: Fondo de Cultura Económica, 1985), 61-94; Elena Hernández Sandoica, Tendencias historiográficas actuales. Escribir historia hoy (Madrid: Akal, 2004), 414-422; François Dosse, «Biographie, prosopographie», en Historiographies Concepts et débats I, eds. Christian Delacroix, François Dosse, Patrick Garcia y Nicolas Offenstadt (Paris: Gallimard [Folio histoire, 179], 2010), 79-85; Emmanuelle Picard, «Du dossier individuel à la prosopographie en histoire de l'éducation: bilan et problèmes de méthode», La Revue Administrative, número monográfico sobre «Les dossiers nominatifs du XIXe siècle. Regards croisés de l'administration sur les personnes», dir. Catherine Mérot (2007): 55-58; Les uns et les autres... Biographies et prosopographies en histoire des sciences, eds. Laurent Rollet y Philippe Nabonnaud (Nancy: Presses Universitaires de Nancy-Éditions Universitaires de Lorraine [Collection «Histoire des institutions scientifiques»], 2012).
} 
Charle, catedrático de Historia contemporánea en la Universidad de París I-Panthéon Sorbonne. ${ }^{10}$

Tras el coloquio de 1984 sobre el personal docente de la enseñanza superior en Francia en los siglos XIX y XX, Christophe Charle ha publicado, sólo o en colaboración, varios diccionarios biográficos relativos al profesorado universitario parisino en los siglos XIX y XX que constituyen valiosas herramientas de trabajo, permitiendo rastrear los orígenes familiares y sociales así como las actividades docentes y fuera de la facultad. Estos diccionarios se refieren primero al profesorado en función en la Facultad de Letras de 1808 a 1939 (con un total de 215 noticias biográficas), ${ }^{11}$ después en la Facultad de Ciencias de 1901 a 1939 (113 fichas), ${ }^{12}$ y finalmente al cuerpo docente de una institución tan específica del «modelo» francés de enseñanza superior como puede ser el Colegio de Francia [Collège de France], también para el periodo de 1901 a $1939 .{ }^{13}$ Con las mismas características y semejante metodología, Françoise Huguet ha proseguido la tarea para los profesores parisinos de la Facultad de Medicina de 1789 a 1939 (con un total de 282 fichas), ${ }^{14}$ André Grelon y Claudine Fontanon para los profesores del

\footnotetext{
${ }^{10}$ Ver Le personnel de l'enseignement supérieur en France aux XIXème et XXème siècles, ed. Christophe Charle y Régine Ferré (Paris: Éditions du CNRS, 1985) y Christophe Charle y Jürgen Schriewer, «Pour une histoire prosopographique comparée des Universités Européennes», en Sozialer Raum und akademische Kulturen. Studien zur europäischen Hochshul-und Wissenschaftgeschichte im 19. Und 20. Jahrundert I À la recherche de l'espace universitaire européen. Études sur l'enseignement supérieur aux XIXe et XXe siècles (Frankfurt Am Main: Peter Lang, 1993), 11-41. Sobre el enfoque prosopográfico dentro de la historiografía universitaria francesa, ver Carolina Rodríguez López, «La historiografía francesa sobre universidades en el siglo XX: las grandes líneas de trabajo», Cuadernos del Instituto Antonio de Nebrija de estudios sobre la Universidad, 3 (2000), 244-250; Guereña, "La historia de la enseñanza superior en Francia. Una aproximación historiográfica», 275-277, y «Las universidades y la enseñanza superior en Francia. Historiografía y líneas de investigación. Nuevas aportaciones», en Historiografía y líneas de investigación en historia de las universidades: Europa mediterránea e Iberoamérica, eds. Luis E. Rodríguez-San Pedro Bezares y Juan Luis Polo Rodríguez (Salamanca: Ediciones Universidad de Salamanca [Miscelánea Alfonso IX, 2011], 2012), 127-128.

${ }^{11}$ Christophe Charle, Les professeurs de la faculté des lettres de Paris, dictionnaire biographique (Paris: Institut National de la Recherche Pédagogique-Centre National de la Recherche Scientifique, 1985 [vol. 1, 1808-1908] y 1986 [vol. 2, 1909-1939]).

12 Christophe Charle y Eva Telkès, Les professeurs de la Faculté des Sciences de Paris 1901-1939. Dictionnaire biographique (Paris: Institut National de la Recherche Pédagogique-Centre National de la Recherche Scientifique, 1989).

${ }^{13}$ Christophe Charle y Eva Telkès, Les Professeurs du Collège de France, 1901-1939. Dictionnaire biographique (Paris: Institut National de la Recherche Pédagogique-Centre National de la Recherche Scientifique, 1988).

${ }^{14}$ Françoise Huguet, Les Professeurs de la Faculté de Médecine de Paris. Dictionnaire biographique, 1789-1939 (Paris: Institut National de la Recherche Pédagogique-Centre National de la Recherche Scientifique, 1991).
} 
Conservatorio Nacional de Artes y Oficios de 1794 a 1955,,$^{15}$ y Jean-François Condette para el profesorado de la Facultad de Letras de Lille bajo la III ${ }^{a}$ República francesa, o sea de 1870 a $1940 .{ }^{16}$

Para el caso español, si bien ya existían sobre el tema algunas iniciativas o sugerencias y observaciones anteriores, ${ }^{17}$ queremos referirnos en particular al Diccionario de catedráticos españoles de Derecho (18471943), albergado actualmente en la página web del Instituto Figuerola de la Universidad Carlos III de Madrid (a la que pertenecen buena parte de los colaboradores del equipo), lo que permite fáciles actualizaciones periódicas. ${ }^{18}$ Investigación colectiva aún en curso iniciada por Carlos Petit, catedrático de Historia del derecho en la Universidad de Huelva sobre la base de un proyecto de investigación titulado «De la enseñanza a la ciencia del Derecho" ${ }^{19}$ el Diccionario de catedráticos pretende reconstruir la trayectoria biográfica del conjunto de los titulares de cátedras jurídicas en España durante casi un siglo, en funciones entre el primer escalafón del cuerpo de catedráticos de universidad elaborado en 1847 y la Ley de Ordenación Universitaria de 1943, o sea de la monarquía de Isabel II al primer franquismo (lo que representa un total de 559 profesores), siguiendo un

\footnotetext{
15 André Grelon y Claudine Fontanon, Les professeurs du Conservatoire national des arts et métiers. Dictionnaire biographique, 1794-1955 (Paris: Institut National de la Recherche Pédagogique-Conservatoire national des arts et métiers, 1994), 2 vols.

16 Jean-François Condette, Les lettrés de la République. Les enseignants de la Faculté des Lettres de Douai puis Lille sous la Troisième République (1870-1940). Dictionnaire biographique (Villeneuve d'Ascq: Université de Lille 3, 2006).

${ }^{17}$ António Hespanha, «L'étude prosopographique des juristes: entre les pratiques et leurs représentations», en El tercer poder: hacia una comprensión histórica de la justicia contemporánea en España, ed. Johannes-Michael Scholz (Frankfurt a.M.: Klostermann, 1992), 93-101; Salvador Albiñana, «Biografía colectiva e Historia de las universidades españolas», en Historia de las universidades modernas en Hispanoamérica. Métodos y fuentes, eds. Margarita Menegus y Enrique González (México: Universidad Nacional Autónoma de México, 1995), 33-82; Llano Torres y Rus Rufino, Historia del pensamiento filosófico y jurídico; Marc Baldó Lacomba, «Profesores de la Facultad de Filosofía y Letras de Valencia, 1857-1900. Esbozo de biografía colectiva», en Colegios y Universidades I. Del antiguo régimen al liberalismo, ed. Enrique González y Leticia Pérez (México: Universidad Nacional Autónoma de México, 2006), 187-214.

$18<$ www.uc3m.es/diccionariodecatedraticos>. Ya informábamos brevemente de la existencia del Diccionario de catedráticos en «Las universidades y la enseñanza superior en Francia. Historiografía y líneas de investigación. Nuevas aportaciones», 128.

${ }^{19}$ En el marco del proyecto de investigación del Ministerio de Ciencia y Tecnología «De la enseñanza a la ciencia del Derecho. E-catálogo de catedráticos, 1857-1943» (DER2008-03069). Según indicaciones de su promotor, en 2011, figuraban ya 111 biografías, en 2012, 210, en 2013, 308, y en septiembre de 2014, 400, lo que indica el rápido ritmo de progresión del Diccionario de catedráticos, en torno a unas cien biografías por año.
} 
mismo modelo organizativo e interpretativo, lo cual permite obviamente realizar todo tipo de comparaciones. ${ }^{20}$

La ficha establecida aborda sucesivamente los elementos siguientes: identificación del personaje, con referencia a su filiación y estado; estudios cursados, del bachillerato al doctorado (con énfasis en el discurso o tesis doctoral), precisando los grados obtenidos y otros datos particulares (como pueden ser las estancias en el extranjero); oposiciones presentadas, tanto las fallidas como las logradas (precisando la asignatura de la misma, la fecha y la composición del tribunal así como el título de la memoria redactada); cátedras desempeñadas así como otros servicios y comisiones especiales; actividades públicas extra-universitarias; principales publicaciones, en particular las relativas a la profesión académica; y, finalmente, fuentes consultadas así como, aunque no siempre, referencias bibliográficas disponibles.

En cuanto a las fuentes primarias utilizadas, se trata esencialmente de los expedientes correspondientes procedentes del Archivo Ministerio de Educación y conservados en el Archivo General de la Administración, situado como bien se sabe en Alcalá de Henares. ${ }^{21}$ En realidad, los expedientes conservados - algunos de los cuales, tales como los de Leopoldo Alas (alias Clarín) [1852-1901] o Miguel de Unamuno [1864-1936], se han publicado en totalidad o en parte- y que cabe consultar son varios. ${ }^{22}$ Aparte de los expedientes personales "generales», con las hojas de servicio de los interesados, existen expedientes particulares referidos a las distintas oposiciones a cátedra — ganadas o no- realizadas por los mismos. Lo que implica tener que consultar varios legajos en función de las diversas oposiciones a las que se presentaron.

\footnotetext{
${ }^{20}$ Sebastián Martín, «De la enseñanza a la ciencia del Derecho: biografía colectiva de juristas españoles (1857-1943)», Cuadernos del Instituto Antonio de Nebrija, 12 (2009): 33-51.

${ }^{21}$ Ver María Carmona de Los Santos, Guía del Archivo Central del Ministerio de Educación y Ciencia (Alcalá de Henares: Ministerio de Educación y Ciencia, 1975), 40 y 62.

${ }^{22}$ Ver, sobre Leopoldo Alas Clarín, Jean-Louis Guereña, «Leopoldo Alas, Catedrático de universidad», en Leopoldo Alas Un clásico contemporáneo (1901-2001). Actas del Congreso celebrado en Oviedo (12-16 de Noviembre de 2001), eds. Araceli Iravedra Valea, Elena de Lorenzo Álvarez y Álvaro Ruiz de la Peña (Oviedo: Universidad de Oviedo, 2002), t. I, 104-133, y Sociabilidad, Cultura y Educación en Asturias bajo la Restauración (1875-1900) (Oviedo: Real Instituto de Estudios Asturianos, 2005), 251-301; y, sobre Unamuno y sus colegas salmantinos de finales del siglo XIX, Jean-Louis Guereña, «El profesorado universitario en el tránsito de los siglos XIX-XX», en Historia de la Universidad de Salamanca. Volumen II: Estructuras y flujos, ed. Luis E. Rodríguez San Pedro Bezares (Salamanca: Ediciones Universidad de Salamanca [Acta Salmanticensia. Historia de la Universidad, 52], 2004), 803-825.
} 
En la página del Diccionario de catedráticos, se pueden realizar búsquedas ordenadas según varios criterios: obviamente primero por orden alfabético de nombres de catedráticos, muchos de ellos poco o nada conocidos desde luego, pero habiendo desempeñado otros un papel central en la historia política, social o cultural de la España contemporánea. Basta con hojear el listado de nombres para percatarse de ello: de Rafael Altamira [1866-1951] a Joaquín Ruiz Giménez [1913-2009] pasando por Francisco Giner de los Ríos [1839-1915] o Luis Jiménez de Asúa [1889-1970], por ejemplo. Desde el punto de vista de las biografías individuales, está claro que el Diccionario de catedráticos trasciende el ámbito universitario propiamente dicho.

Ciñéndonos al espacio universitario, el Diccionario de catedráticos permite también realizar búsquedas por universidades de destino (Barcelona, Granada, La Laguna, Madrid, Murcia, Oviedo, Salamanca, Santiago de Compostela, Sevilla, Valencia, Valladolid y Zaragoza, o sea las diez universidades conservadas en 1845 más las universidades de La Laguna, creada en 1913 y la de Murcia en 1915), reconstituyendo así la historia de las facultades y de las universidades «históricas» y la circulación entre unas y otras, o sea la evolución de las carreras universitarias por periodos históricos.

Otra entrada posible que facilita a los investigadores el Diccionario de catedráticos es la cátedra ejercida por los 559 catedráticos de derecho entre 1847 y 1943. Dichas cátedras vienen agrupadas en catorce categorías bien conocidas que agrupan las principales asignaturas jurídicas: Derecho administrativo, Derecho canónico, Derecho civil, Derecho comparado, Derecho internacional, Derecho mercantil, Derecho natural, Derecho penal, Derecho político, Derecho procesal, Derecho romano, Economía política, Historia del derecho y Oratoria forense. Es de notar que en cada caso se indica con precisión el título exacto de la cátedra correspondiente, en función de los distintos planes de estudio, lo que aporta materiales de interés para la historia disciplinar.

Se ha incluido además en el Diccionario de catedráticos un apartado con todos los catedráticos de Derecho que fueron depurados tras la Guerra Civil por su compromiso con la causa republicana (Rafael Altamira, Demófilo de Buen [1890-1946], Luis García de Valdeavellano [1905-1985], Luis Recaséns [1903-1977], Mariano Ruiz-Funes [1889-1953] o José Ramón Xirau 
[1893-1982], por citar sólo algunos de ellos) o condenados al exilio. ${ }^{23}$ De esta manera, el Diccionario de catedráticos resulta también un instrumento útil para recuperar la «memoria histórica» de la universidad española.

Gracias al Diccionario de catedráticos españoles del Derecho, se dispone por lo tanto - o se dispondrá muy próximamente cuando finalice la redacción del total de las fichas correspondientes $-{ }^{24}$ de una valiosa y fundamental herramienta de trabajo para acercarse a la sociología y al estudio histórico de las profesiones universitarias (jurídicas en este caso) y en general de gran interés no sólo para la historia universitaria estrictamente hablando sino también para la historia intelectual, social y política de España en la época contemporánea.

Convendría desde luego en un horizonte más o menos cercano poder ampliar el Diccionario de catedráticos a otras asignaturas (Medicina en primer lugar), otras épocas y otras categorías docentes, sobre la base de otras fuentes sin duda pero con una metodología idéntica. Los diccionarios biográficos colectivos que se están elaborando para diversas etapas políticas del país, diversas funciones (las de parlamentario, por ejemplo) o diversas comunidades, y en los cuales los universitarios, tanto los profesores como los estudiantes, constituyen elementos de notable importancia por no decir insustituibles por su fuerte presencia, pueden ayudarnos a trabajar en esta dirección.

\section{LAS FUENTES DOCUMENTALES.}

\section{LOS ESCALAFONES DE ANTIGÜEDAD DE LOS CATEDRÁTICOS. EL ENFOQUE «SOCIOLÓGICO»}

Unas de las fuentes primarias manejadas para el establecimiento de tal Diccionario de catedráticos españoles, o mejor dicho para la identificación primera de los catedráticos mismos (de Derecho en este caso) y la elabo-

\footnotetext{
23 Mariano Peset y María Fernanda Mancebo, «Exilio y depuraciones», en Historia de la Universidad de Valencia. Volumen III La Universidad liberal (siglos XIX y XX), ed. Mariano Peset (Valencia: Universitat de València [Col.lecció Cinc Segles, 5-III], 2000), 249-257, y Carolina Rodríguez López, La Universidad de Madrid en el primer franquismo. Ruptura y continuidad (1939-1951) (Madrid: Universidad Carlos III de Madrid-Editorial Dykinson [Biblioteca del Instituto Antonio de Nebrija de Estudios sobre la Universidad], 2002), 285-307.

${ }^{24}$ Como ya se indicó, en septiembre de 2014, se habían redactado 400 fichas biográficas, quedando, pues, 159 para dar por concluido el Diccionario de catedráticos españoles de Derecho (1847-1943) en su formato actual. Está prevista en una fase siguiente la preparación de una versión impresa algo distinta.
} 
ración de la lista alfabética han sido los escalafones de antigüedad de los catedráticos de universidad, publicados anualmente desde 1847, a raíz de las disposiciones dictadas por el Plan Pidal de 1845 y tras un primer «proyecto» realizado en $1846 .^{25}$

En el transcurso del siglo XIX, tras las diversas reformas universitarias que culminaron en el citado Plan Pidal de 1845 y la Ley Moyano de 1857, ${ }^{26}$ y en el marco del proceso de centralización y uniformización llevado a cabo en España con el Estado liberal tras la muerte de Fernando VII en 1833 (sólo subsistieron en efecto diez universidades en toda España como ya queda dicho), el profesorado universitario sufrió profundos cambios que le convirtieron de hecho en mero funcionario estatal, con dos categorías básicas, el catedrático y el profesor auxiliar encargado de suplir las ausencias de los catedráticos, de situación más o menos precaria, ${ }^{27}$ a la espera de llegar a ser algún día catedrático, mediante oposición o concurso. ${ }^{28}$

Desde luego, el catedrático de universidad es la figura más y mejor conocida como cuerpo, gracias en particular a la utilización de los escalafones de

\footnotetext{
${ }_{25}$ Antonio Moreno González, Una ciencia en cuarentena. Sobre la Física en la Universidad y otras instituciones académicas desde la Ilustración hasta la crisis finisecular del XIX (Madrid: Consejo Superior de Investigaciones Científicas [Estudios sobre la Ciencia, 6], 1988), 277-283; Manuel Martínez Neira, Proyecto del escalafón general de los catedráticos de universidad en 1846 (Madrid: Universidad Carlos III de Madrid), 2012, consultado el 10 de julio de 2014 (http://hdl.handle.net/10016/16057); Jean-Louis Guereña, «El primer escalafón de catedráticos de Universidades (1847) y la creación del cuerpo de catedráticos de Universidades en España», en Doctores y Escolares. II Congreso internacional de Historia de las Universidades Hispánicas (Valencia, 1995) (Valencia: Universitat de València [Col.lecció Cinc Segles], 1998), vol. I, 231-250.

${ }^{26}$ Moreno González, Una ciencia en cuarentena, 268-277; Manuel de Puelles Benítez, Estado y educación en la España liberal (1809-1857). Un sistema educativo nacional frustrado (Barcelona: Ediciones Pomares, 2004), 270-296; Manuel Martínez Neira, La creación del cuerpo de catedráticos de universidad (1812-1857) (Madrid, Universidad Carlos III de Madrid [Historia de las Universidades, 33], 2013).

${ }^{27}$ Carmen Rodríguez González, «El profesorado», en Historia de la Universidad de Valladolid, ed. Jesús María Palomares Ibáñez (Valladolid: Universidad de Valladolid, 1989), t. II, 483-515; Francisco Villacorta Baños, «Catedráticos y auxiliares. La formación de los cuerpos burocráticos universitarios (1857-1923)», en L'Université en Espagne et en Amérique latine du Moyen-Age à nos jours. II. Enjeux, contenus, images, ed. Jean-Louis Guereña y Ėve-Marie Fell (Tours: Publications de l'Université de Tours [Série "Études Hispaniques", XIII-XIV], 1998), 151-163.

${ }^{28}$ Mariano Peset Reig, «Oposiciones y selección del profesorado durante los años de la Restauración», Boletín de la Institución Libre de Enseñanza, 2a época, I (2), (1987): 3-28; Blasco Gil, La Facultad de Derecho de Valencia durante la Restauración (1875-1900), 175-237; Manuel Martínez Neira, «Los catedráticos de la posguerra. Las oposiciones a cátedra de historia del derecho en el primer franquismo", Cuadernos del Instituto Antonio de Nebrija de Estudios sobre la Universidad, 6 (2003): 135-220, y La regulación de las oposiciones a cátedras universitarias: 1845-1931 (Madrid: Universidad Carlos III de Madrid [Historia de las Universidades, 35], 2014).
} 
antigüedad. Después de 1847, la confección y la publicación anual del escalafón de antigüedad de los catedráticos de universidades van a formar parte en efecto de las prácticas administrativas en el sector educativo. Una de las dificultades mayores para el investigador reside sin embargo en la localización de tales documentos, pues no se encuentra una serie completa en ninguna biblioteca o archivo, teniendo por lo tanto que acudir a varios centros. ${ }^{29}$

De la primera lista escueta de 1847, pasamos a contar posteriormente con una relación nominal relativamente completa, en la que se ofrecen los datos siguientes: número general en el escalafón (o sea antigüedad en el mismo, partiendo del más antiguo), títulos universitarios, fecha y lugar de nacimiento del interesado, universidades en donde ha servido anteriormente, cátedra que desempeña en la actualidad, facultad, sección (si es el caso) y universidad a las que está adscrito, más una serie de cuadros recapitulativos por universidades, facultades y cátedras.

Sobre la base de esta fuente, a veces combinada con otros documentos, se han realizado ya algunos estudios parciales que demuestran su indudable interés y los resultados que se pueden obtener acerca del cuerpo de catedráticos tras las primeras aportaciones de Mariano Peset en 1984 y de Pedro Luis Moreno y Antonio Viñao Frago en $1985 .{ }^{30}$ Hay que señalar también al respecto el estudio pionero que Fernando Araujo, Jefe de la Sección de estadística en el entonces nuevo Ministerio de Instrucción pública y Bellas Artes, inserta en introducción al escalafón de 1902, con una interesante serie de cuadros estadísticos y de comentarios a los mismos. ${ }^{31}$

Esta fuente oficial, relativamente fiable y homogénea, permite acercarse en efecto a algunas características básicas, de corte sociológico, del cuerpo de catedráticos de universidad: su procedencia geográfica (el lugar de nacimiento), su edad media y la edad de ingreso en el cuerpo, los traslados

\footnotetext{
${ }^{29}$ No se han encontrado como publicaciones impresas los escalafones de antigüedad correspondientes a los años 1854, 1929, 1930 y 1932.

${ }^{30}$ Mariano Peset Reig, «Catedráticos y profesores», en Historia y actualidad de la Universidad española, ed. José Luis Peset (Madrid: Fundación Juan March, 1984), 137-205; Pedro Luis Moreno y Antonio Viñao Frago, «El cuerpo de catedráticos de Universidad como grupo profesional. Análisis sociológico (19071958)», en Higher Education and Society. Historical Perspectives. 7th International Standing Conference for the History of Education (Salamanca: Universidad de Salamanca, 1985), vol. I, 492-502.

${ }^{31}$ Ministerio de Instrucción Pública y Bellas Artes. Subsecretaría.-Sección de Estadística, Escalafón de antigüedad de los catedráticos numerarios de las Universidades del Reino en $1^{\circ}$ de Enero de 1902 (Toledo: Imprenta, Librería y Encuadernación de Rafael G. Menor, 1902), 8-18.
} 
entre universidades y la movilidad académica de los catedráticos dentro del espacio universitario español, en el cual se distinguían claramente universidades «de paso» - como lo fue claramente la universidad de Murcia tras su creación en 1915- y universidades «de destino», y también las remuneraciones correspondientes. ${ }^{32}$

No olvidemos al respecto que el profesorado de la entonces llamada «Universidad Central» era mejor pagado que los de las demás universidades «de provincias», lo que orientaba claramente, junto con otras motivaciones, las carreras universitarias hacia la capital. ${ }^{33}$ El peso y la centralidad de la universidad de Madrid (la Universidad Central del siglo XIX y hoy la Universidad Complutense de Madrid) quedan afirmados, por lo menos hasta 1954, en cuanto a los estudios de doctorado y a la lectura de las tesis doctorales así como a los tribunales de oposición. ${ }^{34}$ La reserva legal de los estudios doctorales a la Universidad de Madrid apareció ya en el Reglamento General de Instrucción Pública de 1821 y luego en el Plan general de estudios de 1845, y tal reserva — con algunas excepciones- se prolongó hasta 1953 o, mejor dicho, hasta el curso académico 1953-1954 que fue cuando se hizo efectiva la descentralización de estos estudios tras más de un siglo de doctorado centralizado. ${ }^{35}$

\footnotetext{
32 Jean-Louis Guereña, «L'université espagnole à la fin du XIXe siècle. Approche sociologique du corps professoral», en L'Université en Espagne et en Amérique latine du Moyen-Age à nos jours. I.-Structures et Acteurs, eds. Jean-Louis Guereña, Ėve-Marie Fell y Jean-René Aymes (Tours: Publications de l'Université de Tours [Série "Etudes Hispaniques", XI-XII], 1991), 225-249, «Los escalafones de antigüedad de los catedráticos de Universidad», en X Coloquio de Historia de la Educación. La Universidad en el siglo XX (España e Iberoamérica). Murcia, 21-24 de septiembre de 1998 (Murcia: Sociedad Española de Historia de la Educación-Departamento de Teoría e Historia de la Educación. Universidad de Murcia, 1998), 532537, "Aproximación sociológica al cuerpo de los catedráticos de universidad a finales del siglo XIX», en Las universidades hispánicas: de la monarquía de los Austrias al centralismo liberal. V Congreso Internacional sobre Historia de las Universidades Hispánicas. Salamanca, 1998, ed. Luis E. Rodríguez San Pedro Bezares (Salamanca: Universidad de Salamanca-Junta de Castilla y León, 2000), t. II, 169-181, «El profesorado universitario en el tránsito de los siglos XIX-XX», y «La Universidad de Oviedo. Aproximación sociológica a su profesorado y proyección social», en Sociabilidad, Cultura y Educación en Asturias bajo la Restauración (1875-1900), 187-352; M ${ }^{\mathrm{a}}$ Fernanda Mancebo, La Universidad de Valencia de la Monarquía a la República (1919-1939) (Valencia: Universitat de València, 1994), 307-314; Blasco Gil, La Facultad de Derecho de Valencia durante la Restauración (1875-1900), 269-393.

33 Ver Paul Aubert, «Madrid, polo de atracción de la intelectualidad española a principios de siglo», en La sociedad española de la Restauración, 1876-1931, (Madrid: Comunidad de Madrid, 1989), 113-122.

${ }^{34}$ Carlos Petit, «La administración y el doctorado: centralidad de Madrid», Anuario de Historia del Derecho Español, 67 (1), (1997): 567-587.

${ }^{35}$ Manuel Martínez Neira, «Sobre el doctorado en derecho en la Salamanca contemporánea», en Juristas de Salamanca, Siglos XV-XX, eds. Salustiano de Dios, Javier Infante y Eugenia Torijano (Salamanca: Ediciones Universidad de Salamanca [Aquílafuente, 152], 2009), 353.
} 
El perfil sociológico del profesorado ha sido abordado, por ejemplo, para intentar dilucidar lo que podría aparecer a primera vista como una paradoja, a propósito del caso ovetense (prácticamente reducido entonces a sus juristas). ${ }^{36}$ La existencia misma a finales del siglo XIX y principios del XX de un llamado "Grupo de Oviedo» dentro de la Universidad de Oviedo, ${ }^{37}$ se puede explicar fácilmente en parte por la gran estabilidad de los profesores ovetenses, pero por supuesto no puede resumirse en ella. En su gran mayoría, el cuerpo profesoral era originario de la región y se identificaba fuertemente con su universidad. Ingresado joven en la carrera, efectuaba la totalidad o la casi totalidad de su servicio en la Universidad de Oviedo. Cuerpo con una gran estabilidad, el envejecimiento progresivo de los catedráticos en funciones en la época estudiada podía dar de temer las peores esclerosis. No fue sin embargo el caso en Oviedo, donde los universitarios supieron dar suficientes pruebas de dinamismo intelectual y social. Uno de ellos, Adolfo Posada [1860-1944], llega a calificarles así de «provincianos con vistas a Europa y a América... al mundo». ${ }^{38}$

Por supuesto, como ya lo hemos indicado, una limitación misma de los escalafones de antigüedad reside en que dejan totalmente de lado a los profesores auxiliares, encargados de suplir las ausencias momentáneas de los catedráticos titulares. ${ }^{39}$ Cabe señalar no obstante que en 1902 se publicó un escalafón, al parecer único, de los profesores auxiliares numerarios, ${ }^{40}$ los «otros profesores», o sea los no catedráticos, entre los cuales iban también a figurar mujeres, durante mucho tiempo excluidas del espacio universitario.

\section{LAS MUJERES UNIVERSITARIAS. DE EXCLUIDAS A PROTAGONISTAS}

Ausentes del Diccionario de catedráticos españoles de derecho por definición, al no poder acceder al cuerpo de los catedráticos/as de Derecho hasta fechas

\footnotetext{
36 Guereña, «La Universidad de Oviedo. Aproximación sociológica a su profesorado y proyección social», 229-242.

${ }^{37}$ Institucionismo y reforma social en España. El Grupo de Oviedo, ed. Jorge Uría (Madrid: Talasa Ediciones, 2000).

${ }_{38}$ Adolfo Posada, Fragmentos de mis Memorias (Oviedo: Universidad de Oviedo, 1983), 178.

39 Blasco Gil, La Facultad de Derecho de Valencia durante la Restauración (1875-1900), 239-258 («Profesores auxiliares de la Facultad»).

${ }^{40}$ Guereña, «Aproximación sociológica al cuerpo de los catedráticos de universidad a finales del siglo XIX», 172.
} 
muy recientes (y por lo tanto no en el periodo contemplado por el Diccionario de catedráticos), las mujeres universitarias existían no obstante pero en otras categorías administrativas que la de los catedráticos de universidad. En efecto, fue sólo en 1964 cuando una mujer accedió por primera vez en España en ser nombrada catedrática en una Facultad de Derecho, Gloria Begué Cantón (nacida en 1931), concretamente en una cátedra de Economía política y Hacienda pública de la Universidad de Salamanca. ${ }^{41}$

Obviamente, antes de poder llegar a ser profesoras, las mujeres habían de entrar primero en la universidad como estudiantes, lo que supuso una lenta y progresiva conquista, no sin obstáculos, desde la primera matrícula oficial de una mujer como estudiante en 1872, pero con permiso especial, hasta el reconocimiento de la igualdad de derechos en el acceso a todos los estudios a partir de 1910, con la feminización progresiva del estudiantado, por lo menos en determinadas facultades. ${ }^{42}$

Si de manera tímida a principios del siglo $\mathrm{xX}$, de forma más masiva durante la Segunda República, penetra, pues, el elemento femenino en las aulas universitarias, antes dominio exclusivo del elemento masculino desde los orígenes mismos de la universidad en la época medieval, otra cosa será que una de ellas (obviamente provista de todos los títulos requeridos) acceda mediante oposición al cuerpo de los catedráticos de universidad, lo que sólo se dará en España en 1953 (concretamente en una cátedra de Historia de la Pedagogía e Historia de la Pedagogía española), con la profesora María Ángeles Galino Carrillo (nacida en 1915), anteriormente profesora ayudante, siendo entonces, y desde 1951, Ministro de Educación Nacional Joaquín Ruiz Giménez y Rector de la Universidad Complutense de Madrid Pedro Laín Entralgo [1908-2001]. ${ }^{43}$

\footnotetext{
${ }^{41}$ Economía, derecho y tributación. Estudios en homenaje a Gloria Begué Cantón, ed. José Ignacio Sánchez Macías, Rafael Calvo Ortega y Fernando Rodríguez López (Salamanca: Ediciones Universidad de Salamanca [Aquílafuente, 92], 2005), 15.

${ }^{42}$ Consuelo Flecha, «Etapas y tendencias de la presencia de la mujer en la Universidad española», en L'Université en Espagne et en Amérique Latine du Moyen Age à nos jours. I. Structures et acteurs, 319-337, y Las primeras universitarias en España 1872-1910 (Madrid: Narcea [Colección Mujeres], 1996); Pilar Ballarín Domingo, «Entre ocupar y habitar. Una revisión historiográfica sobre Mujeres y Universidad en España», Arenal, 17 (2) [Dossier Cien años sin permiso: las mujeres en la Universidad española], (2010): 233-254.

43 Ver una apasionante «conversación» de María Ángeles Galino con Julio Ruiz Berrio y Consuelo Flecha publicada en la revista Historia de la Educación, 26 (2007): 519-538, y Senén Crespo de las Heras y María Cruz del Amo del Amo, «Reconocimiento a María Ángeles Galino: docenta, investigadora y gestora educativa», CEE Participación Educativa, 11 (2009): 175-181.
} 
El caso de la célebre novelista Emilia Pardo Bazán [1851-1921], nombrada en 1916 catedrática de Literatura contemporánea de las lenguas neo-latinas en la Universidad de Madrid, ${ }^{44}$ no resulta en modo alguno significativo, pues se trataba entonces de una medida ad nominen del Ministro de Instrucción Pública de turno (Julio Burell Cuéllar [1859-1919]), pero las oposiciones dentro y fuera de la universidad a tal nombramiento sí resultan claramente reveladoras del estado de la opinión.

Como lo señaló María Ángeles Durán, pionera en los estudios sobre las mujeres en España, en La investigación sobre la mujer en la Universidad española contemporánea (1982), "la opinión pública necesitó de debates, a menudo centrados alrededor de alguna persona o acontecimiento especialmente notorio o brillante, para generar el cambio de actitudes que disminuyera el rechazo hacia aquellas mujeres innovadoras, decididas y marginales» ${ }^{45}$ No cabe duda de que Emilia Pardo Bazán era una de ellas y su nombramiento universitario constituyó uno de los elementos que contribuyeron a mover algo las líneas.

Si hasta mediados del siglo XX las mujeres universitarias no podían acceder, pues, a una cátedra universitaria, no significa que no entraran a formar parte del profesorado universitario, en número reducido desde luego y hasta 1953 tan sólo bajo plazas de profesoras auxiliares o ayudantes a cátedra, categoría docente de nivel inferior, ocupada también por hombres (aspirantes a una cátedra) y que es la menos estudiada y conocida dentro del profesorado universitario, con relación a los catedráticos. ${ }^{46}$

En cuanto a estas primeras profesoras universitarias, es de nuevo Consuelo Flecha, tras haber sacado a la luz las primeras estudiantes, la que se ha lanzado pacientemente a su estudio antes de 1936. Nos muestra que ninguna de aquellas que empezaron su vida profesional antes de 1936 llegó a tener una plaza en propiedad. Y, sobre todo, tras ese acercamiento a un

\footnotetext{
44 Ángeles Quesada Novás, «Una meta alcanzada: la cátedra universitaria de Emilia Pardo Bazán», La Tribuna. Cadernos de estudios da Casa Museo Emilia Pardo Bazán, 4 (2006):43-81; Eva Acosta, Emilia Pardo Bazán La luz en la batalla (Barcelona: Lumen [memorias y biografías], 2007), 535-538; Consuelo Flecha García, «Profesoras en la Universidad. El tránsito de las pioneras en España», Arenal, 17 (2), (2010): 261-264.

45 María Ángeles Durán Heras, La investigación sobre la mujer en la Universidad española contemporánea (Madrid: Ministerio de Cultura, 1982), 26-27.

46 Villacorta Baños, «Catedráticos y auxiliares. La formación de los cuerpos burocráticos universitarios (1857-1923)», 151-163; Guereña, «La universidad: vida universitaria», 166.
} 
centenar de mujeres profesoras universitarias localizadas, concluye que «el crecimiento de profesoras que se ha ido produciendo hasta la actualidad, no ha sido proporcional al aumento del número de universidades, al volumen de estudiantes, a la multiplicación de necesidades docentes e investigadoras». ${ }^{47}$

A las investigaciones pacientemente llevadas a cabo por Consuelo Flecha acerca de las primeras profesoras de las universidades de Barcelona, Granada, Madrid, Murcia, Salamanca, Sevilla, Valladolid y Zaragoza, se puede añadir entre otras las aportaciones de Carolina Rodríguez-López acerca de las primeras profesoras en las facultades madrileñas en los años treinta y de Isabel Ruiz sobre las profesoras ayudantes en la Universidad de Salamanca durante el rectorado de Antonio Tovar [1911-1985], o sea de 1951 a $1956 .{ }^{48}$ También se puede aludir aquí a los trabajos que se han llevado a cabo recientemente acerca de la depuración que sufrieron las mujeres docentes - y por lo tanto las universitarias — al final de la Guerra. ${ }^{49}$

Una primera línea de la investigación —necesaria por cierto y que no pretendemos de modo alguno deconstruir - llevada a cabo acerca de las mujeres universitarias en España ha consistido en una labor casi arqueológica - o al menos archivística- de rescate para conocer y devolver visibilidad a un conjunto de mujeres que pasaban fronteras y superaban obstáculos que podían presentarse en su momento como casi insalvables. Muchos de los estudios realizados insisten en esa calidad de "pioneras»: las primeras matrículas universitarias femeninas, las primeras doctoras, las primeras profesoras, etc...

Nos parece, pues, que hay que intentar ir más allá de la reconstrucción, normalizando en cierta manera un campo de investigación, ampliándolo desde los parámetros de la historia social y cultural, tratando de llegar por ejemplo a la biografía colectiva -o sea lo que se suele calificar de prosopografía, ya bien anclada en los estudios sobre la historia de la

\footnotetext{
47 Flecha García, «Profesoras en la Universidad. El tránsito de las pioneras en España», 260.

48 Carolina Rodríguez-López, «Del pupitre a la tarima. Mujeres, ciencia y universidad en España en el primer tercio del siglo XX: líneas de trabajo y debates», en Presencia y visibilidad de las mujeres: recuperando historia, ed. Rosa María Capel (Madrid: Abada Editores, 2013), 306-310; Isabel Ramos Ruiz, Profesores, alumnos y saberes en la Universidad de Salamanca en el rectorado de D. Antonio Tovar (1951-1956) (Salamanca: Universidad de Salamanca, 2009), 160.

49 Ver Aida Terrón Bañuelos, «Estatuto socioeconómico y activismo sindical del profesorado», en Nuevas miradas historiográficas sobre la educación en la España de los siglos XIX y XX, 200-202.
} 
universidad-, sobre todo a partir del momento en el cual las poblaciones femeninas empiezan a representar una cifra no desdeñable.

Algunas preguntas que nos podemos plantear $-\mathrm{y}$ no se trata de una lista cerrada, ni mucho menos- son por ejemplo las siguientes: ¿Cuáles eran los orígenes sociales de las profesoras y su diversificación? ¿Formaban parte - por el padre o el marido- de lo que podríamos llamar «dinastías universitarias»? Gracias al trabajo de Consuelo Flecha, ${ }^{50}$ conocemos algunas nóminas salariales - modestas-de las primeras profesoras, labor que habría que proseguir a partir del momento en el que las mujeres acceden por fin al estatus de catedráticas. A partir de la segunda mitad del siglo XX, y como se ha hecho a partir de la segunda mitad del siglo XIX para los catedráticos sobre la base de los escalafones, se podría intentar reconstruir entonces la edad media de acceso al cuerpo, la evolución de la carrera universitaria y sus diferencias o retrasos con la de sus homólogos masculinos (el famoso «techo de cristal»), o sea una aproximación sociológica de conjunto al profesorado universitario femenino...

¿Cuáles podían ser por fin las formas de compromiso social y político de las mujeres universitarias (estudiantes y profesoras), dentro del feminismo organizado desde luego (A.N.M.E., Cruzada de Mujeres...) pero también fuera de éste, incluyendo las organizaciones femeninas católicas y de derecha? ${ }^{51}$ ¿Cuáles fueron sus formas públicas de expresión, en la prensa, en publicaciones de todo tipo (incluyendo libros de texto y obras literarias), y, ya en una época más actual, en el parlamento u otros foros?

O sea que la historia de las mujeres universitarias (como en general cualquier temática relativa a la historia de la educación) no debe a nuestro parecer aislarse de todos los conjuntos sociales, culturales y políticos en los cuales están presentes —oausentes, segúnlos momentosylas circunstanciasde una manera u otra. En todo caso, el taller de investigación relativo a las mujeres universitarias queda abierto a nuevas perspectivas y temáticas — de poder ser, con puntos de vista comparativos frente a otras realidades- que permitan entender plenamente las «conquistas» y las «discriminaciones» de las mujeres en el espacio universitario.

\footnotetext{
${ }^{50}$ Flecha García, «Profesoras en la Universidad. El tránsito de las pioneras en España», 266-268, 270279, 283, 286, 292 у 295.

${ }^{51}$ Ver Inmaculada Blasco, Paradojas de la ortodoxia. Política de masas y militancia católica femenina en España (1919-1939) (Zaragoza: Prensas Universitarias de Zaragoza [Sagardiana, 3], 2003).
} 


\section{LA «CONDICIÓN UNIVERSITARIA». HACIA UNA «HISTORIA SOCIAL» DEL PROFESORADO UNIVERSITARIO}

Aparte de la historia del profesorado universitario que podríamos calificar de «externa» (o sea académica), nos parece que hay que ir también a una historia «interna» del mismo, integrando el estudio de la «condición universitaria», ${ }^{52}$ enfocando las condiciones de vida de los catedráticos y otros profesores pero también su cultura, sus tradiciones, sus ritos, sus formas de comportamiento en general — que conforman lo que algunos han calificado de «tribu universitaria»—, ${ }^{53}$ para llegar a una real aproximación social y cultural del profesorado universitario en su conjunto.

Acerca del origen social de los catedráticos, una variable importante para esbozar un estudio prosopográfico y que no precisan los escalafones de antigüedad, teniéndose que acudir por lo tanto a otras fuentes, se indica para el caso valenciano - pero, ¿difería mucho de los demás? - que «coincide con el de sus alumnos: capas medias y propietarios, con especial incidencia de los hijos de las profesiones liberales, que saben apreciar el valor de los estudios». ${ }^{54}$ En la Facultad de Ciencias, por ejemplo, entre 1857 y 1936, más de la mitad de los catedráticos eran hijos de médicos, abogados, catedráticos, farmacéuticos o comerciantes. Una tercera parte procedía de familias de comerciantes y propietarios, y el resto eran hijos de «labradores», una categoría desde luego un tanto ambigua. ${ }^{55}$ Se trata naturalmente de estudios que cabe proseguir y ampliar desde el punto de vista cronológico.

Un estudio modélico al respecto, que merecería proseguirse, es el realizado sobre la «cultura doméstica» del profesorado vallisoletano en el siglo XIX, sobre la base de inventarios post-mortem encontrados en el archivo de protocolos. ${ }^{56}$ También disponemos de algunas indicaciones acerca de las

\footnotetext{
52 Ver, sobre el caso francés, Paul Gerbod, La condition universitaire en France au XIXe siècle (Paris, Presses Universitaires de France, 1965).

53 Alejandro Nieto, La tribu universitaria. Fenomenología de los catedráticos de la Universidad española (Madrid: Tecnos, 1984).

54 Marc Baldó Lacomba y María Fernanda Mancebo Alonso, "Los profesores», en Historia de la Universidad de Valencia. Volumen III La Universidad liberal (siglos XIX y XX), ed. Mariano Peset (Valencia: Universitat de València [Col.lecció Cinc Segles, 5-III], 2000), 76.

55 Ernest Sánchez Santiró, Científics i professionals. La Facultat de Ciències de València (1857-1939) (Valencia: Universitat de València, 1998), 114-116.

56 Rosa Ma Dávila Corona, «La cultura doméstica del profesorado vallisoletano en la segunda mitad del siglo XIX», en Las universidades hispánicas: de la monarquía de los Austrias al centralismo liberal, $127-138$.
} 
bibliotecas de los profesores madrileños en el siglo XIX. ${ }^{57}$ Señalemos por otra parte un novedoso enfoque en torno a los espacios y a los tiempos universitarios decimonónicos..$^{58}$

El acceso a memorias y autobiografías de profesores, así como la utilización de literatura de ficción y de documentos iconográficos de todo tipo, permitiría incidir en la vida cotidiana del profesorado universitario. ${ }^{59} \mathrm{Un}$ primer elemento sería el estudio de manuales universitarias y de apuntes de clase para conocer la "práctica pedagógica» del profesorado universitario. ${ }^{60}$ Hasta fechas relativamente recientes, y salvo excepciones notables, la enseñanza solía realizarse demasiado con compendios generales, en clases fundamentalmente teóricas y memorísticas, siguiendo con la práctica del temario, herencia de la enseñanza catequística y las asignaturas y los programas no incorporaban los conocimientos modernos, sobre todo los científicos, y especialmente los venidos desde fuera, hasta relativamente tarde.

La producción científica de los universitarios era prácticamente nula y los libros de texto utilizados en clase solían reducirse a repeticiones poco originales. ${ }^{61}$ No olvidemos por otra parte que, como en los otros niveles de enseñanza, las autoridades educativas controlaban durante parte del siglo XIX la producción de manuales universitarios que debían de quedar autorizados en listas publicadas periódicamente. ${ }^{62}$

\footnotetext{
57 Jesús A. Martínez Martín, Lectura y lectores en el Madrid del siglo XIX (Madrid: Consejo Superior de Investigaciones Científicas [Biblioteca de Historia, 11],1991), 91-124.

58 José María Hernández Díaz, «Espacios y tiempos en la Universidad de la España del XIX (1845-1898)», en Las universidades hispánicas: de la monarquía de los Austrias al centralismo liberal, 217-233.

${ }^{59}$ Sobre autobiografías en el mundo hispánico y su interés para la historia de la Educación, ver Jean-Louis Guereña, «Les écrits autobiographiques comme source pour de l'éducation dans l'Espagne contemporaine», en Résistances et exils, ed. Marie-Claude Chaput y Bernard Sicot (l'Histoire Nanterre, Publidix. Université de Paris X-Nanterre [Regards/8], 2005), 39-69. Sobre representaciones literarias, ver José Antonio Cieza García, «Intelectuales y Universidad. Las letras españolas ante el problema universitario durante el primer tercio del siglo XX», en Higher Education and Society. Historical Perspectives, vol. II, 141-157.

${ }^{60}$ Mariano Peset, "Cuestiones sobre la investigación de las facultades de derecho durante la segunda mitad del siglo XIX», en I Seminario de historia del derecho y derecho privado. Nuevas técnicas de investigación (Bellaterra, Universidad Autónoma de Barcelona, 1985), 327-396; Manuales y textos de enseñanza en la Universidad Liberal. VII Congreso internacional sobre la historia de las universidades hispánicas, ed. Manuel Ángel Bermejo Castrillo (Madrid: Universidad Carlos III de Madrid-Editorial Dykinson [Biblioteca del Instituto Antonio de Nebrija $n^{\circ}$ 13], 2004).

${ }^{61}$ Manuel Martínez Neira, El estudio del Derecho. Libros de texto y planes de estudio en la universidad contemporánea (Madrid: Universidad Carlos III-Editorial Dykinson [Biblioteca del Instituto Antonio de Nebrija de estudios sobre la universidad, 4], 2001.

${ }^{62}$ Ver José Luis Villalaín Benito, Manuales escolares en España. Tomo I: Legislación (1812-1939) (Madrid:
} 
También cabe acercarse a la inserción del profesorado universitario en la ciudad, en sus distintos espacios de sociabilidad — como los casinos y ateneos en los cuales participaba- y de poder - prensa periódica, publicaciones, cargos oficiales en la administración o en la política, tribuna parlamentaria...-.63 Pero obviamente desbordamos de esta manera el mero campo universitario en el cual pretendemos movernos, pues, amén de intelectual, el universitario es también un ciudadano, más o menos comprometido en la vida social y política española, sea a escala local, regional o nacional (y a veces internacional).

No abordamos aquí el tema de las asociaciones profesionales y del sindicalismo ni tampoco el de las luchas por la autonomía universitaria y la libertad de cátedra, que también desborda el marco que nos hemos asignado pero que evidentemente le está muy relacionado. Son bien conocidos por otra parte los movimientos intelectuales, como la célebre Institución Libre de Enseñanza [la ILE] y sus numerosas iniciativas, que contribuyeron a la modernización de la universidad y también del país y en los cuales colaboraron muchos universitarios. Del mismo modo, cabe apuntar tan sólo el proceso de politización que afecta también al profesorado en determinadas coyunturas políticas, como durante la Segunda República y obviamente el periodo de la Guerra ${ }^{64}$ En sus múltiples facetas, la historia del profesorado universitario incide, pues, en el conjunto de la historia social, política y cultural del país.

\footnotetext{
Universidad Nacional de Educación a Distancia [Serie "Proyecto Manes"], 1997), Manuales escolares en España. Tomo II: Libros de texto autorizados y censurados (1833-1874) (Madrid: Universidad Nacional de Educación a Distancia [Serie "Proyecto Manes"], 1999) y Manuales escolares en España. Tomo III: Libros de texto autorizados y censurados (1874-1939) (Madrid: Universidad Nacional de Educación a Distancia [Serie "Proyecto Manes"], 2002). Para el caso de los manuales de Literatura durante la monarquía de Isabel II, ver Jean-Louis Guereña, «La política de regulación de los manuales para la enseñanza superior en España. El caso de los manuales de Literatura en la Facultad de Filosofía (1846-1867)», en Dalla pecia all'e-book. Libri per l'Università: stampa, editoria, circolazione e lettura. Atti del Convegno internazionale di studi. Bologna, 21-25 ottobre 2008, eds. Gian Paolo Brizzi y Maria Gioia Tavoni (Bologna: CLUEB [Centro interuniversitario per la storia delle università italiane, Studi 11], 2009), 499-512.

${ }^{63}$ Ver, para la Restauración, Elena Hernández Sandoica, «Universidad y Política en la España del siglo XIX: Madrid (1875-1898)», en L'Université en Espagne et en Amérique Latine du Moyen Age à nos jours. II. Enjeux, contenus, images, 165-183 y, acerca de la universidad de Sevilla de 1900 a 1923, Nieves Gómez García, «Universidad y vida cotidiana: estudio aproximativo de la relación Universidad/Ciudad en la Sevilla de 1900 a 1923», en X Coloquio de Historia de la Educación. La Universidad en el siglo XX, 522-531.

${ }^{64}$ María Pilar Hernando Serra, «Catedráticos y política durante la Segunda República», en Permanencia y cambio. I Universidades hispánicas 1551-2001, eds. Enrique González González, Enrique y Leticia Pérez Puente (México: Universidad Nacional Autónoma de México. Centro de Estudios sobre la Universidad, 2005), vol. I, 419-443, y «Profesores contra la República», en Ciencia y Academia. IX Congreso internacional de historia de las universidades hispánicas (Valencia, Septiembre 2005) (Valencia: Universitat de València, 2008), vol. I, 475-492.
} 


\section{ALGUNOS ELEMENTOS EN CONCLUSIÓN}

Pese a que siguen existiendo algunas lagunas en las líneas de investigación seguidas en este campo de investigación, el balance final que podemos trazar de la historiografía acerca del profesorado universitario en la España contemporánea resulta relativamente esperanzador, en cantidad y también en calidad, si bien cabe reconocer que no todos los trabajos realizados valen al respecto en igual medida.

En el marco de una investigación colectiva ya madura, se ha avanzado notablemente, no sólo en el conocimiento - tanto cuantitativo como cualitativo- de estos actores claves de la vida universitaria en varios periodos históricos de la España contemporánea - principalmente durante la Restauración y también durante el franquismo, esencialmente de 1939 a 1956-, sino también en su interpretación y modo de abordarlos.

El destacado papel de muchos universitarios en la vida intelectual y política del país —o simplemente a escala local — ha llevado desde luego al estudio biográfico de muchas personalidades universitarias de primer plano (por ejemplo, en los casos de Miguel de Unamuno o José Ortega y Gasset), pero se trata de analizar aquí su faceta universitaria, si bien resulta difícil separarla totalmente de las demás. En buena parte, la historia de los universitarios es en efecto la historia de las élites (políticas, intelectuales, profesionales...) que se está elaborando progresivamente para el caso español. ${ }^{65}$

Como lo demuestra la realización del Diccionario de catedráticos españoles de Derecho (1847-1943), la historia del profesorado universitario ha de ser desde luego una empresa colectiva y también interdisciplinar (historia del Derecho, historia de la Educación, historia general y también historia de la Medicina, historia de la Ciencia e historia de la Literatura), pese a que las lógicas administrativas universitarias - y, no lo olvidemos, las fuentes de financiación- no siempre contribuyan a ello.

Nos parece finalmente que la perspectiva comparada, primero dentro de España misma pero también fuera de sus fronteras y dentro del espacio

\footnotetext{
${ }^{65}$ Elites. Prosopografía contemporánea, ed. Pedro Carasa Soto (Valladolid: Universidad de Valladolid [Serie Historia y Sociedad, no 42], 1994); «A vueltas con el sujeto», ed. Joseba Agirreazkuenaga, Tema monográfico de la revista Historia Contemporánea, 13-14 (1996): 17-349; Els intel.lectuals i el poder a Catalunya. Materials per a un assaig d'història cultural del món català contemporani (1808-1975), ed. Jordi Casassas (Barcelona: Enciclopedia Catalana, 1999).
} 
europeo en un primer tiempo, ha de representar otra necesaria etapa para adentrarnos en una adecuada y razonada comprensión de la vida universitaria en su conjunto, siempre teniendo en cuenta, por supuesto, la necesaria periodización histórica, y pasando por lo tanto de una historia parcelaria de las universidades, de la que sólo hemos abordado aquí una parte, la referida a su profesorado, a una historia al mismo tiempo global y plural de la universidad en el marco de la sociedad de su tiempo.

\section{Nota sobre los autores:}

Antiguo miembro de la Casa de Velázquez (Madrid), Jean-Louis Guereña es en la actualidad catedrático emérito de Civilización española contemporánea de la Universidad François-Rabelais de Tours. En dicha universidad, ha sido el cofundador del CIREMIA (Centro Interuniversitario de Investigación sobre Educación y Cultura en el Mundo Ibérico e Iberoamericano). Es asesor científico del Centro de Historia universitaria Alfonso IX (Universidad de Salamanca) y del Centro de investigación MANES (Manuales escolares españoles) de la UNED (Madrid). En el campo de la historia de la educación, se ha interesado particularmente por la estadística escolar, la sociabilidad, educación popular, los manuales escolares (urbanidad, retórica y literatura, Quijote), el profesorado universitario, la educación sexual y la historiografía educativa, temas sobre los cuales ha publicado varios trabajos en español o en francés y ha editado varios libros colectivos o números monográficos de revistas. 